\title{
(2) OPEN ACCESS \\ Prevalence and causes of blindness and visual impairment; and cataract surgical services in Katsina state of Nigeria
}

\author{
Manal Omran Taryam, ${ }^{1}$ Muhammad M Rabiu (1) , ${ }^{1}$ Nasiru Muhammad, ${ }^{2,3}$ \\ Kehinde Oladigbolu, ${ }^{4}$ Halima Abdurrahman ${ }^{5}$
}

\begin{abstract}
${ }^{1}$ Noor Dubai Foundation, Dubai Health Authority, Dubai, United Arab Emirates

${ }^{2}$ Ophthalmology Unit, Surgery Department, Usmanu Danfodiyo University, Sokoto, Nigeria ${ }^{3}$ Ophthalmology Department, Usmanu Danfodiyo University Teaching Hospital, Sokoto, Nigeria

${ }^{4}$ Department of Ophthalmology, Ahmadu Bello University Teaching Hospital, Zaria, Nigeria ${ }^{5}$ Katsina Eye Center, Katsina State Government, Dandagoro, Nigeria
\end{abstract}

Correspondence to

Dr Muhammad M Rabiu, Noor Dubai Foundation, Dubai Health Authority, Dubai, United Arab Emirates;

muhammad.rabiu@noordubai. ae

Received 13 May 2019 Revised 24 July 2019 Accepted 20 August 2019 Published Online First 5 September 2019

\section{ABSTRACT}

Aim To generate data on blindness and visual impairment for planning and monitoring a

comprehensive eye care programme in Katsina state of Nigeria.

Method A rapid assessment of avoidable blindness (RAAB) survey methodology was used to select 3120 persons aged 50 years and over. The sample was selected using a multistage cluster randomised sampling. Each participant had visual acuity and lens assessment. Persons with vision less than $6 / 12$ in any eye were assessed for the cause of visual impairment. Persons with cataract were asked why they had not had surgery. Data were captured electronically with the mRAAB Androidbased software and analysed with STATA V.14 software. Results A response rate of $90.1 \%$ was achieved. The age-sex adjusted blindness prevalence was 5.3\% (95\% Cl 5.2\% to 5.3\%). Women were $30 \%$ more likely to be blind (OR 1.3, 95\% Cl 1.2 to 1.3). The principal causes of blindness were cataract (70\%), other posterior segment (12\%) and glaucoma (7\%); $86.7 \%$ of blindness was avoidable. The prevalence of cataract blindness is $2.6 \%$ (95\% Cl $2.5 \%$ to $2.6 \%$ ) with higher odds in women (OR $1.2,95 \% \mathrm{Cl} 1.2$ to $1.3, \mathrm{p}<0.005)$. The cataract surgical coverage $<6 / 60$ for persons was $28.2 \%$ and women were $45 \%$ less likely to have had cataract surgery (OR $0.55,95 \% \mathrm{Cl} 0.34$ to $0.78, \mathrm{p}<0.005$ ). The major barriers to cataract surgery are lack of felt need and the cost of services.

Conclusion Katsina state of Nigeria has high burden of avoidable blindness affecting more women. The state eye care programme should have cataract services that are more accessible, affordable and gender sensitive.

\section{INTRODUCTION}

Since the launch of the WHO VISION 2020: The Right to Sight programme in $1999,{ }^{1}$ stakeholders have collaborated globally to establish or support eye care services. In Nigeria, several nongovernmental organisations have collaborated with many state governments (like Cross River, Kaduna, Kwara and Sokoto states) to establish eye care programmes aiming for an eye care service that is accountable, affordable, equitable, integrated and sustainable. $^{23}$

The World Health Assembly resolution WHA66.4 $4^{4}$ of 2013 urged Member States of the WHO to generate evidence on the magnitude and causes of blindness and visual impairment (VI) for planning and monitoring of eye care services.
Evidence-based eye planning is expected to achieve universal eye health in Member States as contained in the resolution.

The Katsina State Government of Nigeria in collaboration with Noor Dubai Foundation, a United Arab Emirates-based charity, is planning to establish an eye care programme in the state. However, Katsina state of Nigeria has no recent data on magnitude and causes of blindness and VI. The last reported prevalence of blindness and visual impartment from a subdistrict of the state was two decades ago, which reported blindness prevalence of $8.2 \%$ (95\% CI $5.8 \%$ to $10.5 \%)$ and low vision of $6.9 \%$ (95\% CI $4.7 \%$ to $9.2 \%$ ) among 40 years and older. ${ }^{5}$ Thus, a study was commissioned to generate these data for evidence-based planning and monitoring of the proposed eye care programme towards the attainment of Universal Eye Health in the state. The study was also to determine the extent to which cataract services have met the needs in the society and the barriers to uptake of cataract surgery in the state.

\section{METHODS AND MATERIALS}

This was a cross-sectional study of persons aged 50 years and over residing in Katsina state of Nigeria. The WHO-recommended rapid assessment of avoidable blindness (RAAB) ${ }^{467}$ methodology was used to conduct the study as it provides a more cost-effective approach to generating data on blindness and VI compared with a full epidemiological survey. Data collection took place in November and December 2018. Study participants were informed of the purpose of the study in the local Hausa language, and a signature or thumb print was obtained from them for acceptance to participate. The provisions of the Declaration of Helsinki were also applied regarding the right to participate or to withdraw at any stage of the study.

A minimum sample size of 3030 was obtained based on the following variables: target population of 466578 aged 50 years and older representing $6.9 \%$ of estimated total population of 6740481 in the state as of $2011 .^{8}$ Estimated prevalence of blindness in persons 50 years and over of 5.6\% as reported in recent survey in neighbouring districts of Sokoto state. ${ }^{3}$ Maximum tolerable error of $5.6 \% \pm 1$. A design effect of 1.4 and non-response rate of 5\% were applied.

The study sample was selected using multistage cluster randomised sampling. Using probability 
proportional to cluster size sampling, 78 communities were randomly selected in the first sampling stage as clusters. In the second sampling stage, each cluster was divided into segments comprising 40 persons aged 50 years and over. Where there was more than one segment, a segment was selected by simple random sampling. All eligible persons in the selected segment were then enumerated until the desired cluster sample size is attained (40). In a segment with less than 40 eligible persons, a nearby segment was selected to complete the cluster sample. Only persons aged 50 years and over who are residents in the selected segment for at least 6 months were invited to participate in the study. Ages of most people had to be approximated by important local calendar events due to non-documentation of births in the area.

The presenting vision (visual acuity, VA) of each participant was tested using a single optotype E-chart. The chart has a single 60 size optotype on one side and a 12 size optotype on the other side. Each eye was tested separately. The direction of the E was randomly changed five times for the reading of the study participants. An eye was considered to pass an acuity line after correctly identifying four of five directions of the optotypes shown. Any eye that failed to identify the 6/12 optotype had pinhole acuity assessment. An ophthalmic nurse conducted the VA assessment. Lens examination was then performed by the ophthalmologist using a penlight to determine if an eye has the natural crystalline lens, intraocular lens or is aphakic/pseudophakic. Those with a VA of less than 6/12 with pinhole were further evaluated to determine the cause of VI for each eye and for the person using the WHO algorithm. ${ }^{9}$ The evaluation included direct and indirect ophthalmoscopy with pupil dilation (with Tropicamide $1 \%$ eye-drops) if required, after confirming the anterior angle is not shallow. Where there is more than one possible cause of VI in any eye, the disease most curable was considered, otherwise the most easily preventable was selected. For each person the cause of VI was determined by considering the causes in the two eyes and selecting the cause that is most curable, otherwise the easily preventable cause. Those diagnosed with cataract in any eye as the cause of VA $<6 / 12$ were asked why they had not had surgery. Up to two barriers to accessing cataract surgery were selected. Persons who had cataract surgery were asked when and where they had surgery and the cost of the surgery. The operational definitions were based on RAAB operational definitions. ${ }^{10}$ Participant(s) identified with eye diseases were referred to nearby eye clinics for further care.

Three teams collected the data and each team comprised an ophthalmologist, an ophthalmic nurse, a driver and a local guide. A certified RAAB trainer trained the teams on RAAB survey procedures and operational definitions in 6 days. This was conducted in a general hospital and in a nearby non-survey community for field training. A minimum intergrader agreement of 0.7 on VA, lens assessment and cause of VI with the RAAB trainer was achieved before the survey started.

All collected data were electronically captured with the aid of the mRAAB software on an Android phone by all three teams and sent to the survey's principal investigator, who cleaned the data by using the consistency check of the RAAB software. The data were analysed using STATA V.14. Age and sex-adjusted prevalence was calculated in Microsoft Excel using the 2011 Katsina state population estimates. ${ }^{8}$ Tests of statistical significance were conducted to determine level of statistical significance between groups at $\mathrm{p}<0.05$. Blindness was defined as presenting VA of $<3 / 60$ in the better eye; severe visual impairment (SVI) as a VA of $<6 / 60-3 / 60$ in the better eye; and early to moderate VI (EMVI) as a VA of $<6 / 12-6 / 60$ in the better eye. 'All VI' as VA less than $6 / 12$ to no perception of light. The cataract surgical coverage (CSC) for persons and eyes was calculated using the following formula: ${ }^{11}$

Cataract Surgical Coverage (persons) $(V A)=(x+y / x+y+z) \times 100$,

where: $\mathrm{x}=$ persons with unilateral (pseudo)aphakia and operable cataract in the other eye; $y=$ persons with bilateral (pseudo) aphakia; $\mathrm{z}=$ persons with bilateral operable cataract.

Cataract Surgical Coverage (eyes) $(V A)=(a / a+b) \times 100$,

where: $a=$ (pseudo)aphakic eyes; $b=$ eyes with operable cataract.

\section{RESULTS}

Of the 3120 enumerated, 2812 persons were examined (response rate of $90.1 \%)$ as in table 1 . Males constituted $51.2 \%$ of the examined (1441 of 2812). Because the ages of participants were estimates, a tendency towards rounding up age and underestimation was observed.

\section{Prevalence of blindness and VI}

The unadjusted prevalence of blindness with available correction was $5.4 \%$ (95\% CI $4.6 \%$ to $6.3 \%)$; SVI was $2.3 \%$ (95\% CI $1.8 \%$ to $2.9 \%$ ); EMVI was $23.5 \%$ (95\% CI $21.9 \%$ to $25.1 \%$ ).

The age-sex adjusted blindness prevalence for the population was $5.3 \%(95 \%$ CI $5.2 \%$ to $5.3 \%)$, SVI was $1.8 \%(95 \%$ CI $1.8 \%$ to $1.8 \%)$ and EMVI was $19.1 \%(95 \%$ CI $19.0 \%$ to $19.2 \%)$ (table 2). The odds of blindness in women was $1.3(95 \%$ CI 1.2 to 1.3) compared with men. There was a strong association at $\mathrm{p}<0.05$ between being female and blindness $(\mathrm{p}<0.005)$. However, the difference in prevalence of EMVI and SVI among the sexes is not statistically significant.

\section{Causes of blindness and VI}

The principal causes of bilateral blindness were cataract, other posterior segment and glaucoma accounting for $88.8 \%$ of

Table 1 Examination status of eligible persons

\begin{tabular}{|c|c|c|c|c|c|c|c|c|c|}
\hline \multirow[b]{2}{*}{ Age group (years) } & \multicolumn{3}{|l|}{ Examined } & \multicolumn{2}{|c|}{ Not available } & \multicolumn{2}{|l|}{ Refused } & \multicolumn{2}{|c|}{ Not capable } \\
\hline & Males (n) & Females (n) & Total (\%) & Males (n) & Females (n) & Males (n) & Females (n) & Males (n) & Females (n) \\
\hline $50-54$ & 263 & 312 & $575(20.4)$ & 18 & 35 & 3 & 8 & 0 & 0 \\
\hline $55-59$ & 269 & 309 & $578(20.5)$ & 20 & 22 & 5 & 6 & 0 & 3 \\
\hline $60-64$ & 257 & 297 & $554(19.7)$ & 38 & 22 & 6 & 9 & 0 & 3 \\
\hline $65-69$ & 200 & 158 & $358(12.7)$ & 23 & 8 & 2 & 6 & 0 & 0 \\
\hline $70-74$ & 209 & 120 & $329(11.7)$ & 28 & 8 & 3 & 2 & 1 & 0 \\
\hline $75-79$ & 112 & 49 & $161(5.7)$ & 2 & 1 & 3 & 1 & 0 & 1 \\
\hline $80+$ & 131 & 126 & $257(9.1)$ & 5 & 4 & 1 & 4 & 1 & 6 \\
\hline Total & $1441(51.2 \%)$ & 1371 (48.8\%) & $2812(100)$ & 134 & 100 & 23 & 36 & 2 & 13 \\
\hline
\end{tabular}


Table 2 Sex-adjusted prevalence and magnitude of blindness and visual impairment

\begin{tabular}{|c|c|c|c|c|c|c|}
\hline & \multicolumn{2}{|l|}{ EMVI } & \multicolumn{2}{|l|}{ SVI } & \multicolumn{2}{|c|}{ Blindness } \\
\hline & $\mathrm{n}$ & $\%(95 \% \mathrm{Cl})$ & $\mathrm{n}$ & $\%(95 \% \mathrm{Cl})$ & $\mathrm{n}$ & $\%(95 \% \mathrm{Cl})$ \\
\hline Male & 52206 & 19.2 (19.0 to 19.3$)$ & 5166 & 1.9 (1.8 to 2.0$)$ & 13867 & $5.1(5.0$ to 5.2$)$ \\
\hline Female & 36988 & 19.0 (18.8 to 19.2$)$ & 3309 & 1.8 (1.6 to 1.8$)$ & 10707 & 5.5 (5.4 to 5.6$)$ \\
\hline Total & 89194 & 19.1 (19.0 to 19.2$)$ & 8476 & 1.8 (1.8 to 1.8$)$ & 24574 & $5.3(5.2$ to 5.3$)$ \\
\hline
\end{tabular}

EMVI, early to moderate visual impairment; SVI, severe visual impairment.

blindness as in table 3 . About $86.7 \%$ of the causes of blindness are avoidable. The principal causes of EMVI were cataract and refractive errors accounting for $87 \%$ of the causes.

The leading causes of unilateral blindness were cataract (56.7\%), glaucoma $(9.1 \%)$ and non-trachomatous corneal opacity $(8.9 \%)$ while the leading causes of unilateral 'All VI' were cataract (63.1\%) and refractive errors (21.6\%).

\section{Cataract blindness}

The sex-adjusted bilateral cataract prevalence was 2.6\% (95\% CI $2.5 \%$ to $2.6 \%$ ). There is a very strong evidence of a statistically significant difference at $\mathrm{p}<0.05$ between the sexes with females having a $20 \%$ higher odds of prevalence of cataract blindness (OR 1.2, 95\% CI 1.2 to $1.3, \mathrm{p}<0.005)$. An estimated 224454 eyes of 143944 persons in the target population are in need of cataract surgery to treat blindness or VI in one or both eyes (table 4).

\section{Cataract surgical coverage}

The CSC for persons and eyes for VA $<6 / 60$ is $28.2 \%$ and $23.4 \%$, respectively, as in table 5 . Women were $45 \%$ less likely to have had cataract surgery compared with men with a statistically significant difference at $\mathrm{p}<0.05$ (OR $0.55,95 \%$ CI 0.34 to 0.78 , $\mathrm{p}<0.005)$. Among all the eyes that had cataract interventions in the last 5 years, $86.6 \%$ of the eyes had cataract surgery while the remaining $13.4 \%$ had couching. However, for eyes that had

Table 3 Principal causes of blindness and visual impairment with available correction

\begin{tabular}{|c|c|c|c|c|}
\hline & EMVI & SVI & Blind & All VI \\
\hline Cause & $\begin{array}{l}<6 / 12-6 / 60 \\
\mathrm{n}(\%)\end{array}$ & $\begin{array}{l}<6 / 60-3 / 60 \\
\mathrm{n}(\%)\end{array}$ & $\begin{array}{l}<3 / 60 \\
\mathrm{n}(\%)\end{array}$ & $\begin{array}{l}<6 / 12-\mathrm{NPL} \\
\mathrm{n}(\%)\end{array}$ \\
\hline Cataract & $447(66.5)$ & $39(76.5)$ & $100(69.9)$ & $586(67.7)$ \\
\hline Refractive error & $137(20.4)$ & $0(0)$ & $1(0.7)$ & $138(15.9)$ \\
\hline Glaucoma & $10(1.5)$ & $4(7.8)$ & $10(7.0)$ & $24(2.8)$ \\
\hline Non-trachoma CO & $14(2.1)$ & $2(3.9)$ & $5(3.5)$ & $21(2.4)$ \\
\hline $\begin{array}{l}\text { Cataract surgical } \\
\text { complications }\end{array}$ & $15(2.2)$ & $0(0)$ & $2(1.4)$ & $17(2.0)$ \\
\hline Trachoma CO & $2(0.3)$ & $1(2.0)$ & $5(3.5)$ & $8(0.9)$ \\
\hline Uncorrected aphakia & $1(0.1)$ & $0(0)$ & $1(0.7)$ & $2(0.2)$ \\
\hline Diabetic retinopathy & $1(0.1)$ & $1(2.0)$ & $0(0)$ & $2(0.2)$ \\
\hline $\begin{array}{l}\text { AR macular } \\
\text { degeneration }\end{array}$ & $2(0.3)$ & $0(0)$ & $0(0.0)$ & $2(0.2)$ \\
\hline $\begin{array}{l}\text { All globe/CNS } \\
\text { abnormalities }\end{array}$ & $1(0.1)$ & $0(0)$ & $1(0.7)$ & $2(0.2)$ \\
\hline Phthisis & $0(0)$ & $0(0)$ & $1(0.7)$ & $1(0.1)$ \\
\hline $\begin{array}{l}\text { Other posterior } \\
\text { segment }\end{array}$ & $42(6.3)$ & $4(7.8)$ & $17(11.9)$ & $63(7.3)$ \\
\hline Total & $672(100)$ & $51(100)$ & $143(100)$ & $866(100)$ \\
\hline
\end{tabular}

$A R$, age related; $C N S$, central nervous system; $C O$, corneal opacity; EMVI, early to moderate visual impairment; NPL, no perception of light; SVI, severe visual impairment; $\mathrm{VI}$, visual impairment. cataract interventions more than 5 years ago, only $52.1 \%$ had cataract surgery while $47.9 \%$ had couching. Couching is a traditional form of treating cataract involving blunt dislocation of the crystalline lens into the vitreous cavity of the eye.

Majority of those operated for cataract had free surgery $(63 \%$, 104 of 165 ), with only $27 \%$ (44 of 165 ) paying for the surgery. Most cataract surgeries were conducted in a charitable hospital (38\%), government hospital (31\%) and eye camps (22\%). Only $8 \%$ (15 of 178$)$ were performed in private hospitals.

\section{Outcome of cataract surgery}

With available correction, $38 \%$ of pseudophakic eyes had a postoperative VA of $\geq 6 / 12$ (normal vision) that increased to $53 \%$ with pinhole correction. For 'couched' eyes, however, only $3.5 \%$ of the eyes had a VA of $\geq 6 / 12$ with available correction that increased to $8.8 \%$ with pinhole correction. Visual outcome after cataract surgery was poor (VA <6/60) in $19.2 \%$ of the pseudophakic eyes with available correction that reduced to $7.9 \%$ with pinhole correction, whereas $84.2 \%$ of the couched eyes had poor outcome with available correction which reduced to $65 \%$ with pinhole correction.

\section{Causes of poor visual outcome in pseudophakic eyes}

The causes of 'Poor' and 'Borderline' visual outcome in pseudophakic eyes are mainly due to ocular comorbidity (43\%) and surgery-related complications (40\%). Out of the 78 eyes with 'Borderline outcome' (VA <6/12-6/60) the main causes were 'Ocular co-morbidity' (42.3\%) and 'Uncorrected refractive error' (33.3\%). The main causes of poor visual outcome (VA $<6 / 60$ ) were ocular comorbidity $(42 \%)$ and operative complications (40\%).

\section{Barriers to cataract surgery}

The major barriers to cataract surgery are a lack of felt need for improvement in vision by the participants because of ageing $(38 \%)$ and the cost of services (35\%). There was no significant difference between the sexes. However, among those with vision worse than 6/60 'Cost' was the major barrier (33\%), while for those with vision better than 6/60 the major barrier was 'Need not felt' $(52.5 \%)$. There is no difference across the sexes for the different VA levels.

\section{DISCUSSION}

The response rate of $90.1 \%$ in the study is good although we had projected to achieve $95 \%$ coverage of the selected population. The underachievement was due to the absence of $7 \%$ of the sample population who were out harvesting their farm produce. The good response obtained in this study is attributable to good mobilisation and cooperation received from local authorities and the study participants. The population distribution suggests an under-representation of persons in the age group of 50-54 years. The lack of birth certificate resulted in age estimation that showed a tendency to push the age to mid-60s or late 60 s. 
Table 4 Extrapolation of number of people and eyes with cataract blindness and visual impairment in the state

\begin{tabular}{|c|c|c|c|c|c|c|}
\hline & \multicolumn{2}{|l|}{ EMVI } & \multicolumn{2}{|l|}{ SVI } & \multicolumn{2}{|c|}{ Blindness } \\
\hline & $\mathrm{n}$ & $\%(95 \% \mathrm{Cl})$ & $\mathrm{n}$ & $\%(95 \% \mathrm{Cl})$ & $n$ & $\%(95 \% \mathrm{Cl})$ \\
\hline \multicolumn{7}{|c|}{ Bilateral cataract } \\
\hline Male & 36229 & 13.3 (13.2 to 13.4$)$ & 3208 & 1.2 (1.1 to 1.2$)$ & 6416 & 2.3 (2.3 to 2.4 ) \\
\hline Female & 26553 & 13.6 (13.4 to 13.8$)$ & 2424 & $1.2(1.2$ to 1.3$)$ & 5680 & 2.9 (2.8 to 3.0$)$ \\
\hline Total & 62782 & 13.4 (13.3 to 13.5$)$ & 5632 & 1.2 (1.1 to 1.2$)$ & 12096 & 2.6 (2.5 to 2.6 ) \\
\hline \multicolumn{7}{|c|}{ Cataract eyes } \\
\hline Male & 106989 & 39.3 (39.1 to 39.5$)$ & 7737 & 2.8 (2.8 to 2.8$)$ & 16417 & 6.0 (5.9 to 6.1$)$ \\
\hline Female & 71991 & 37.0 (36.8 to 37.2 ) & 6268 & 4.0 (3.9 to 4.1$)$ & 15052 & 7.7 (7.6 to 7.8$)$ \\
\hline Total & 178980 & 38.4 (38.2 to 38.5$)$ & 14005 & $3.0(2.9$ to 3.0$)$ & 31469 & 6.7 (6.7 to 6.8 ) \\
\hline
\end{tabular}

$\%$ denotes prevalence; $\mathrm{n}$ refers to number of people in the state.

EMVI, early to moderate visual impairment; SVI, severe visual impairment.

The prevalence of blindness in this study is lower than was reported two decades ago from a district of the state $(8.2 \%$ for persons 40 years and older). ${ }^{5}$ However, the prevalence is similar to the finding of the more recent Nigerian national survey $(5.5 \%) .^{12}$ Some improvements in eye health services and resources in the state over the last two decades might have resulted in decrease burden of blindness. Currently there are six ophthalmologists working in two optimally equipped eye clinics in the state compared with two decades ago when there was only one ophthalmologist with one poorly equipped eye clinic. The major causes of blindness and SVI in the study compare to the finding in a nearby population where cataract-related causes constituted $72.5 \%$ of causes of blindness. ${ }^{13}$ Cataract and refractive error alone are responsible for over $86 \%$ of all forms of VI in the study area. This suggests that even though there may have been improvement in eye services in the state over the last two decades, these services are still suboptimal as basic uncorrected refractive error is not being adequately addressed. Fortunately, there are proven cost-effective interventions for these two conditions. This should be prioritised in the proposed eye care programme for the state.

The prevalence of cataract blindness in this study area is higher than that reported in neighbouring Sokoto state $(1.9 \%) .{ }^{13}$ The CSC for persons (VA <6/60) for the study area $(28 \%)$ is much lower than the findings in neighbouring Sokoto state of Nigeria $(62 \%){ }^{13}$ and also in Tanzania $(65 \%)^{14}$ and Nakuru, Kenya $(71 \%) .{ }^{15}$ Even though this coverage rate was a remarkable improvement from surgical coverage of $4 \%$ reported about two decades ago in a subdistrict of the state, ${ }^{5}$ it is still very low. This is more relevant considering the fact that the study area has had free mass cataract surgery services at the state capital for more than 5 years until recently when partial payment of N6000 (US\$16.5 equivalent) was introduced to sustain the services. However, as these surgeries were carried out only in the state capital, transport costs to reach the service may have been an obstacle in a state with a large land mass of over $24000 \mathrm{~km}^{2}$ and poor transportation network. Indeed, cost of accessing cataract services featured as a major barrier to having cataract surgery among the study population. In contrast, the cataract services in the neighbouring Sokoto state, which reported a higher surgical coverage, ${ }^{13}$ were based on outreach services whereby cataract surgeries are taken to the remote rural areas and were offered for a longer period of time. This indicates the need for an eye care programme with strengthened cataract surgical services by decentralising the services to be more accessible and affordable to remote areas.

Similar to findings in this study several reports in the literature had reported women with higher prevalence of blindness ${ }^{1416}$ and cataract blindness but lower odds of cataract surgery uptake. ${ }^{12}$ Male dominance, lack of financial resources, illiteracy and lack of information have been identified as potential factors resulting in this gender imbalance. ${ }^{17}$ In this study, due to a unique demographic structure of the area characterised by higher percentage of male population than females, the absolute number of cataract blind men was more than females. All the same, proactive approach to women blindness and cataract may be more beneficial for advocacy and for resource mobilisation and because women in such rural communities are already disadvantaged by discrimination rooted in sociocultural factors. ${ }^{18}$ The higher burden of blindness and cataract prevalence among women in the state may be addressed by using women case finders and provision of cataract surgery fee subsidy for them.

The visual outcome with available correction in pseudophakic eyes is comparable to the finding in nearby districts of Sokoto state $\left(18 \%\right.$ poor outcome). ${ }^{19}$ But the major causes of poor outcome in this study including couched eyes were ocular comorbidity, surgery-related complications and uncorrected refractive error. There is a need for the proposed eye care programme to support surgeons on appropriate patient selection, institute cataract services self-auditing and refresher courses to reduce

Table 5 Cataract surgical coverage (CSC) by persons and eyes

\begin{tabular}{|c|c|c|c|c|c|c|}
\hline \multirow[b]{2}{*}{ Visual acuity } & \multicolumn{3}{|c|}{ CSC persons } & \multicolumn{3}{|c|}{ CSC eyes } \\
\hline & $<6 / 12$ & $<6 / 60$ & $<3 / 60$ & $<6 / 12$ & $<6 / 60$ & $<3 / 60$ \\
\hline \multicolumn{7}{|l|}{ Males } \\
\hline Cataract surgical coverage (\%) & 14.1 & 33.7 & 36.3 & 15.1 & 28.9 & 31.9 \\
\hline \multicolumn{7}{|l|}{ Females } \\
\hline Cataract surgical coverage (\%) & 8.2 & 21.7 & 23.4 & 6.3 & 17.3 & 19.0 \\
\hline \multicolumn{7}{|l|}{ Total } \\
\hline Cataract surgical coverage (\%) & 11.3 & 28.2 & 30.4 & 10.1 & 23.4 & 25.8 \\
\hline
\end{tabular}


surgery-related complications especially in the government hospitals where majority of the complications occurred. Routine use of biometry, availability of intraocular lenses of all powers and promoting use of spectacles can improve the proportion of eyes/persons with good surgical outcome in the study area.

Other posterior segment disorders apart from glaucoma, diabetic retinopathy and age-related macular degeneration that constituted $11.9 \%$ of blindness could not be determined in the study. As such, another study is needed to be able to determine what these posterior segment diseases are.

The findings of this study buttress the necessity for implementation of a comprehensive eye care programme in Katsina state with emphasis on provision and decentralisation of cataract and refractive error services. The programme should include patient education and subsidy especially for females towards achieving universal health coverage. This study was limited by imprecise age estimation resulting in over-representation or under-representation of certain age groups and use of basic eye examination such that other posterior segment disorders could not be ascertained. The high response, however, support the generalisability of the results to reflect the VI and cataract surgical services situation in Katsina state.

\section{CONCLUSION}

The prevalence of blindness and cataract blindness in the population is high and the causes of blindness are mostly avoidable with a gender inequality in the prevalence of blindness and uptake of cataract services. More efforts are necessary to increase awareness and accessibility and improve gender equity in cataract and other eye health services.

Acknowledgements We acknowledge and thank Dr Abduljalil Abdullahi, Dr Ahmed Hamza, Dr Ado Abdu and other staff of the Katsina State Ministry of Health, Katsina State Hospital Management Board, the Executive Secretary of Katsina State Primary Health Development Agency, the survey ophthalmic nurses, survey assistants, the survey drivers and the communities visited. We especially thank the study participants for their acceptance to take part in this study.

Contributors This research was conducted with the approval and technical support of the Katsina State Government. Study conception: MOT, MMR. Study design: MOT, MMR, NM. Data collection: KO, HA, NM. Data analysis: NM, MMR. First article draft: MOT, NM, MMR. Article review: MMR, NM, KO, HA.

Funding This study was funded by the Noor Dubai Foundation, UAE.

Competing interests None declared.

Patient consent for publication Not required.

Ethics approval The Human Research and Ethics Committee of the Katsina State Ministry of Health (Katsina MOH/ADM/SUB/1152/1/181) granted ethical approval for the study.

Provenance and peer review Not commissioned; externally peer reviewed.
Data availability statement Data are available upon request.

Open access This is an open access article distributed in accordance with the Creative Commons Attribution Non Commercial (CC BY-NC 4.0) license, which permits others to distribute, remix, adapt, build upon this work non-commercially, and license their derivative works on different terms, provided the original work is properly cited, appropriate credit is given, any changes made indicated, and the use is non-commercial. See: http://creativecommons.org/licenses/by-nc/4.0/.

\section{ORCID iD}

Muhammad M Rabiu http://orcid.org/0000-0002-1311-5507

\section{REFERENCES}

1 WHO. Prevention of blindness and visual impairment: what is vision 2020? 2019 Available: https://www.who.int/blindness/partnerships/vision2020/en/ [Accessed 25 Mar 2019].

2 Kolawole 00. Case study: improving the management of eye care programmes. Community Eye Health 2008;21:60-1.

3 Muhammad N, Adamu M, Mpyet C, Caleb M, et al. Impact of a 10-year eye care program in sokoto, Nigeria: changing pattern of prevalence and causes of blindness and visual impairment. Middle East Afr J Ophthalmol. In Press 2019;26:101-6.

4 World Health Organization. Universal eye health - a global action plan 2014-2019. Geneva, 2013: 28p.

5 Rabiu MM. Cataract blindness and barriers to uptake of cataract surgery in a rural community of northern Nigeria. Br J Ophthalmol 2001;85:776-80.

6 Kuper H, Polack S, Limburg H. Rapid assessment of avoidable blindness. Community Eye Health 2006;19:68-9.

7 British council for prevention of blindness. RAAB. Available: https://www.cehjournal. org/resources/raab/ [Accessed 16 Jul 2019].

8 National Bureau of Statistics (Nigeria). Annual Abstract of statistics, 2012, 2014: 1-619.

9 World Health Organization. Coding Instructions for the WHO/PBL eye examination record (version III). Vol. 1. PBL. Geneva: WHO, 1988.

10 Limburg H, Ing WM, Kuper $\mathrm{H}$, et al. Rapid assessment of avoidable blindness version 6, 2013. Available: https://www.cehjournal.org/resources/raab/ [Accessed $18 \mathrm{Mar}$ 2019].

11 Limburg H, Foster A. Cataract surgical coverage: an indicator to measure the impact of cataract intervention programmes. Comm Eye Health 1998;11:03-6.

12 Rabiu MM, Kyari F, Ezelum C, et al. Review of the publications of the Nigeria national blindness survey: methodology, prevalence, causes of blindness and visual impairment and outcome of cataract surgery. Ann Afr Med 2012;11:125-30.

13 Muhammad N, Mansur R, Dantani A, et al. Prevalence and causes of blindness and visual impairment in Sokoto state, Nigeria: baseline data for vision 2020: the right to sight eye care programme. Middle East Afr J Ophthalmol 2011;18:123-8.

14 Habiyakire C, Kabona G, Courtright P, et al. Rapid assessment of avoidable blindness and cataract surgical services in Kilimanjaro region, Tanzania. Ophthalmic Epidemiol 2010;17:90-4

15 Mathenge W, Kuper $\mathrm{H}$, Limburg $\mathrm{H}$, et al. Rapid assessment of avoidable blindness in Nakuru district, Kenya. Ophthalmology 2007;114:599-605.

16 Randrianaivo J-B, Anholt RM, Tendrisoa DL, et al. Blindness and cataract surgical services in Atsinanana region, Madagascar. middle East Afr J Ophthalmol. Medknow Publications 2014;21:153-7.

17 WHO. Gender and blindness. Available: https://apps.who.int/iris/bitstream/handle/ 10665/68885/a85574.pdf [Accessed on 12 Apr 2019].

18 WHO. Available: www.who.int/topics/women_health [Accessed on 16 Jul 2019].

19 Muhammad N, Adamu MD, Caleb M, et al. Changing patterns of cataract services in north-west Nigeria: 2005-2016. PLoS One 2017:12:e0183421. 